\title{
Editorial
}

\section{Current Trends in the Study of Child Temperament}

\author{
Marcel Zentner \\ University of Geneva, $\mathrm{CH}$, and University of York, UK
}

The concept of temperament, classically understood as referring to consistent variations in moods and behavior with neurobiological foundations, has a history dating back to antiquity. However, the beginnings of the systematic, longitudinal study of infant and child temperament are typically associated with the New York Longitudinal Study, launched by Thomas and Chess in the mid-50s. This work spurred increasing interest in the topic among U.S. researchers, leading to the development of several programs of research during the 1980s. Today, temperament is a well-established topic in child and developmental psychology. This can be gleaned from the space devoted to temperament in the most recent edition of the third volume of the Handbook of Child Psychology, which exceeds the space devoted to any other topic in the volume. Along with two chapters devoted to child temperament (Kagan \& Fox, 2006; Rothbart \& Bates, 2006), a third chapter on personality development also covers temperament in childhood extensively (Caspi \& Shiner, 2006).

There are reasons for this prominence. Beyond its traditional role in child and developmental psychology, research on child temperament has branched into genetics, neurobiology, developmental psychopathology, and personality. For research on affective-behavioral outcomes of genetic polymorphisms, temperament is among the most obvious phenotypes to study. Early temperamental dispositions have also been shown to play a significant role in the development of psychopathology, leading to much interest in child temperament among psychiatrists. Finally, research on child temperament has provided the most comprehensive taxonomy for the description of individual differences in childhood that, broadly, relate to domains of affect, activation, and attention. Against this background of fervent activity, it is difficult to understand why interest in this area languishes among European developmentalists, most notably German-speaking ones. In 2007, the program books of the biennial meetings of the Society for Research in Child Development (SRCD) in Boston, and the biennial meeting of its German counterpart, the Tagung der Fachgruppe Entwicklungspsychologie in Heidelberg, showed a ratio of presentations on temperament of $116: 0$.

The neglect of temperament in German-speaking countries is all the more surprising because the modern, systematic research on infant and child temperament may be said to have originated in Switzerland. The protagonist of this unwritten chapter in the history of modern temperament research was Richard Meili (1900-1991), ${ }^{1}$ a Swiss

\footnotetext{
${ }^{1}$ One of Meili's closest collaborators in the 1960s-Prof. Alfred Lang-was so kind as to confirm the exactitude of the following account.
}

European Journal of Developmental Science [EJDS]. 2008, Vol. 2, No. 1/2, 2-6

(C) Vandenhoeck \& Ruprecht GmbH \& Co. KG, Göttingen 2008, ISSN 1863-3811 
psychologist and professor at the University of Berne from 1949 until his retirement in 1970. An expert in intelligence and aptitude testing, Meili's research focus shifted to the development of personality (or character, as it was called then) soon after resuming his new post in Berne. In 1950, he set out to examine potential infant reactivity precursors of later personality differences with a sample of 26 infants. Initially, Meili found most behaviors to be random and too unstable to be potential markers of later personality. Eventually, however, he made a discovery that he briefly relates in one of the rare passages of his longitudinal work ever translated into English: "Meili (1957) discovered a difference between responses to an object in children between three and four months of age; some after initial inhibition rapidly resumed a calm expression, relaxed and sometimes smiled; others remained tense, moved irritably and began to cry" (Meili, 1963/1968, p. 245). Meili interpreted these reactions in terms of differences in the ease of processing novel objects - a dimension he assumed to be "characterologically relevant" (Meili, 1953, 1957). On this assumption, Meili followed these children into adolescence. He found moderate-to-high correlations between tenseness at 3 to 4 months of age and multiple inhibition and shyness measures at the ages of 7 and 15 years. Meili replicated these findings with a new, larger sample of 41 infants that were followed into school age (Meili \& Meili-Dworetzki, 1972).

Inadequate methods sometimes discredit early efforts in a given area, efforts that can then be either ignored or treated as historical curiosities. Meili’s methods, however, were relatively advanced for his time. Striving for a degree of objectivity and exactitude that impressed his peers (Piaget, 1970) but exasperated his students, Meili had all the infants' behaviors filmed and coded from record. The infants' reactions to novelty were examined four times on separate days to see whether they were consistent (they tended to be; see Pulver, 1959). At school age and adolescence, behavioral observations in the laboratory were combined with observations in natural settings, teacher and parent reports, and performance on various standardized psychological tests. Drawing from his background in test construction and factor analysis, Meili provided nuanced statistical analyses of the data. Of course, distinctively modern as his research approach was, Meili could still have gotten things wrong. However, given that recent research on infancy precursors of behavioral inhibition has come out with similar findings, there is little reason to think so (Zentner \& Bates, 2008, pp. 12-13 \& 17).

Why, then, is Meili's work on early infancy precursors of child and adolescent shyness not better known? Contemplating this question can yield insights into the divide between the United States and many European countries in matters of child temperament research. Clearly, the lack of a translation for Meili's books and journal articles did not help his case. However, the diffusion of his innovative research was perhaps more seriously curtailed by his German-speaking peers and students. Unfortunately for Meili, research on temperament concepts went gradually out of fashion in post-war Germany. This decline happened in part because work on "character" must have appeared epigonal to the Charakterologie (characterology or psychology of character) - a pre-war product that was eventually reinforced by a French 
branch, the florid caractérologie. Theoretically and qualitatively oriented, this work was perceived to carry little promise for the advancement of psychology as a modern science. More important, the notion of constitutionally based character types that could be ranked on an evaluative scale linked to race must have held little appeal to psychologists working in post-war Germany.

A combination of these factors instilled a deep-seated skepticism toward temperament concepts in an entire generation of German-language psychologists. The way in which temperamental concepts are qualified in a widely consulted and academic psychology dictionary (Brockhaus) provides a telling example: "Today, such biologisms are considered outdated and politically dangerous, because they can foster the discrimination of people based on physical attributes" (Starke-Perschke, 2001, p. 608; translation by M.Z., italics added). Indeed, in other popular academic dictionaries, research on temperament is presented as a subject of, at most, archeological interest (see Fröhlich, 2005, p. 474; Häcker, Stapf, \& Dorsch, 2004, p. 942). Thus, the reader is extensively informed about Galen's humoral temperament typology, along with references to Sheldon's and Kretschmer's constitutional typology, the latter of which is listed among "modern" temperament conceptions in one of the entries (Fröhlich). Brief notes on work by Guilford, Cattell, or Eysenck usually conclude the entries. Another classical reference, Städtler's (1998) 1200-page Lexikon der Psychologie, does not even have an entry for "temperament." The fate of Meili's work, then, serves as a reminder of the difficulty of establishing scientific facts if they do not coincide with the prevalent interests and values of a given context and historical era.

Against the backdrop of the imbalance of research activity on infant and child temperament in the USA and in Europe over the last half-century, I was pleased to be given the opportunity to prepare a special issue on child temperament for the European Journal of Developmental Science. Although a growing number of developmentally oriented psychologists and psychiatrists across Europe have started to assimilate current temperament concepts and research into their own work, the assimilation rambles and does not reflect the breadth of the field. Thus, when preparing this issue, a major aim was to solicit submissions that could reflect some of this breadth.

The first contribution (Zentner \& Bates, 2008) provides a background for the articles to follow by offering a review of concepts, research programs, and measures in the child temperament area. The second, third, and fourth articles are concerned with the biological foundations of temperament, though in different, complementary ways. Whereas Kagan (2008) assesses recent findings related to the neurochemistry of temperament, especially as they relate to genetic polymorphisms, Ruf and collaborators (Ruf, Schmidt, Lemery-Chalfant, \& Goldsmith, 2008) present new behavior genetic data on impulsivity and inattention-two components of temperament that have become prime subjects for research, in part due to their potential role in the genesis of attention deficit hyperactivity disorder (ADHD). In the subsequent review, Huizink (2008) shows that in addition to genetics and neurobiology, prenatal 
influences constitute a third category of biological influences on early temperament, though these influences are often environmentally induced.

The next three articles show that, against a common prejudice, contemporary research on temperament is firmly rooted in an interactionist view of psychological development. In this view, temperamental predispositions and the environment are equipollent, continuously interacting forces in human development. The study by Goodnight, Bates, Pettit, and Dodge (2008) represents a continuation of a tradition of research on the relationship between temperament and parenting style interactions carried out by the same group as well as by other groups (see Zentner \& Bates, 2008). However, in contrast to previous research that focused on interactions between the child's temperament and preexisting parenting styles, the current research addresses how parents' self-initiated efforts (campaigns) to cope with their child's temperamental characteristics affect the development of externalizing symptoms.

The subsequent review article by McClowry, Rodriguez, and Koslowitz (2008) shows that parents (as well as teachers) can be effectively trained to improve their responses to a child's temperament. McClowry describes her own intervention program, "Insights," along with other approaches, all of which point to the benefits of integrating knowledge about individual differences in temperament into global parenting programs. The contribution that follows by Super and colleagues (2008) elucidates a third way in which the context interacts with temperament. Their study adds new substance to previous work suggesting that the same temperamental characteristics are seen as more or less difficult around the world depending on a temperament-culture match. The current collection of articles closes with an article by Shiner and Madsen (2008) that addresses an intriguing question in research on child temperament, namely, how child temperament relates to childhood personality and how, in turn, childhood personality relates to adult personality.

Although space limitations dictated that not all recent research developments could be represented with a special contribution in this issue, the introductory review article draws attention to some developments not covered in this collection. Thus, I am confident that the reader who goes through this issue and has the patience to keep on reading additional references included in the following articles should get a fair notion of current trends in the study of child temperament.

\section{References}

Caspi, A., \& Shiner, R. L. (2006). Personality development. In W. Damon \& R. Lerner (Series Eds.), \& N. Eisenberg (Vol. Ed.), Handbook of child psychology: Vol. 3. Social, emotional, and personality development (6th ed., pp. 300-365). New York: Wiley.

Fröhlich, W. (2005). Wörterbuch Psychologie [Psychology dictionary] (23rd ed.). Munich, Germany: DTV.

Goodnight, J.A., Bates, J.E., Pettit, G.S., \& Dodge, K.A. (2008). Parents' campaigns to reduce their children's conduct problems: Interactions with temperamental resistance to control. European Journal of Developmental Science, 2, 100-119. 
Häcker, H., Stapf, K., \& Dorsch, F. (2004). Psychologisches Wörterbuch [Psychology dictionary] (14th fully revised and expanded edition). Bern, Switzerland: Huber.

Huizink, A.C. (2008). Prenatal stress exposure and temperament: A review. European Journal of Developmental Science, 2, 77-99.

Kagan, J. (2008). The biological contributions to temperaments and emotions. European Journal of Developmental Science, 2, 38-51.

Kagan, J., \& Fox, N. (2006). Biology, culture, and temperamental biases. In W. Damon \& R. Lerner (Series Eds.), \& N. Eisenberg (Vol. Ed.), Handbook of child psychology: Vol. 3. Social, emotional, and personality development (6th ed., pp. 99-166). New York: Wiley.

McClowry, S.G., Rodriguez, E.T., \& Koslowitz, R. (2008). Temperament-based intervention: Re-examining goodness of fit. European Journal of Developmental Science, 2, 120-135.

Meili, R. (1953). Beobachtungen über charakterologisch relevante Verhaltensweisen im dritten und vierten Lebensmonat [Observations of characterologically relevant behaviors in the third and fourth month of life]. Schweizerische Zeitschrift für Psychologie [Swiss Journal of Psychology], 12, 257-275.

Meili, R. (1957). Anfänge der Charakterentwicklung [Beginnings of character development]. Bern, Switzerland: Huber.

Meili, R. (1968). The structure of personality (A. Spillmann, Trans.). In J. Nuttin, P. Fraisse, \& R. Meili (Eds.), Motivation, emotion and personality (pp. 192-282). London: Routledge \& Kegan Paul. (Original work published 1963).

Meili, R. \& Meili-Dworetzki, G. (1972). Grundlagen individueller Persönlichkeitsunterschiede [Foundations of individual personality differences]. Bern, Switzerland: Huber.

Piaget, J. (1970). Preface. Festschrift für Richard Meili. Schweizerische Zeitschrift für Psychologie [Swiss Journal of Psychology], 29.

Pulver, U. (1959). Untersuchung zur Irritierbarkeit bei Säuglingen [A study on irritability in infants]. Schweizerische Zeitschrift für Psychologie [Swiss Journal of Psychology], 18, 18-33.

Rothbart, M. K., \& Bates, J. E. (2006). Temperament. In W. Damon \& R. Lerner (Series Eds.), \& N. Eisenberg (Vol. Ed.), Handbook of child psychology: Vol. 3. Social, emotional, and personality development (6th ed., pp. 99-166). New York: Wiley.

Ruf, H.T., Schmidt, N.L., Lemery-Chalfant, K., \& Goldsmith, H.H. (2008). Components of childhood impulsivity and inattention: Child, family, and genetic correlates. European Journal of Developmental Science, 2, 52-76.

Shiner, R.L. \& Madsen, A.S. (2008). Personality in childhood: A bridge from early temperament to adult outcomes. European Journal of Developmental Science, 2, 158-175.

Städtler, T. (1998). Lexikon der Psychologie. Stuttgart, Germany: Kröner Verlag.

Starke-Perschke, S. (2001). Der Brockhaus. Menschliches Fühlen, Denken und Verhalten verstehen [The Brockhaus: Understanding human feeling, thinking and behavior]. Mannheim, Germany: Brockhaus.

Super, C.M., Axia, G., Harkness, S., Welles-Nyström, B., Zylicz, P.O., Parmar, P., Bonichini, S., Bermúdez, M.R., Moscardino, U., Kolar, V., Palacios, J., Eliasz, A., \& McGurk, H. (2008). Culture, temperament, and the "difficult child": A study in seven western cultures. European Journal of Developmental Science, 2, 136-157.

Zentner, M. \& Bates, J.E (2008). Child temperament: An integrative review of concepts, research programs and measures. European Journal of Developmental Science, 2, 7-37. 